\title{
Healthcare Provider Group
}

National Cancer Institute

\section{Source}

National Cancer Institute. Healthcare Provider Group. NCI Thesaurus. Code C93394.

A collection of healthcare providers loosely based upon a criterion (i.e., specialty, department, credentials). 